\title{
Treatment of Hypernatremia in Breastfeeding Neonates: A Systematic Review
}

\author{
Adrianne Rahde Bischoffa ${ }^{a}$ Alícia Dorneles Dornelles ${ }^{b}$ \\ Clarissa Gutierrez Carvalhoc, d \\ aDepartmental Clinical Fellowship, Division of Neonatology, Department of Pediatrics, \\ University of Toronto and the Hospital for Sick Children, Toronto, ON, Canada; \\ bPrograma de Pós-Graduação em Saúde da Criança e do Adolescente, and 'Departamento \\ de Pediatria, Faculdade de Medicina, Universidade Federal do Rio Grande do Sul, and \\ dServiço de Pediatria, Hospital de Clínicas de Porto Alegre, Porto Alegre, Brazil
}

\begin{abstract}
What Is It about?
Hypernatremic dehydration in term neonates is classically associated with inadequate fluid intake, particularly in breastfed infants. Although the literature proposes a maximum rate of serum sodium ( $\mathrm{SNa}$ ) reduction, there is no consensus about proper rehydration strategies in hypernatremic neonates. Both the degree of hypernatremia and the rate of SNa drop during treatment are key players in the development of serious adverse effects. We highlight the importance of conducting well-designed studies in order to elucidate remaining questions.
\end{abstract}

\section{Key Words}

Hypernatremic dehydration - Hypernatremia treatment - Term neonates · Serum sodium .

Cerebral edema $\cdot$ Breastfeeding

\section{Abstract}

Background/Aims: Hypernatremic dehydration in term neonates is associated with inadequate fluid intake, usually related to insufficient lactation. The use of hypotonic fluids is appropriate to dilute serum sodium ( $\mathrm{SNa}$ ), but cerebral edema may develop when it happens abruptly. Our objective was to clarify how to correct hypernatremic dehydration properly. Methods: The following databases were searched, limited to studies published until January 31st, 2016: Clinical Trials, MEDLINE/PubMed, EMBASE, LILACS, and the Cochrane Library. We included open-label trials, nonrandomized controlled trials, or prospective and retrospective

A.R.B. and A.D.D. contributed equally to this work. 
case series evaluating relevant outcomes. Information regarding the way of administering the treatment, type of fluid used, rates of complications and outcomes, as well as the rate of SNa reduction were collected. Results: Searches yielded 771 articles: 64 had the full text reviewed and 9 were included. No randomized clinical trials or systematic reviews focusing on treatment of hypernatremic dehydration and its outcomes were found. We found a scarcity of high quality studies and great methodology heterogeneity. Conclusions: More severe hypernatremia is at greater risk of causing severe adverse effects of treatment. There is no consensus about the optimal rate of SNa drop in this population, but a slower correction appears to be safer. Questions as when parenteral fluids are indicated remain unanswered.

(C) 2017 The Author(s)

Published by S. Karger AG, Basel

\section{Introduction}

Hypernatremic dehydration (serum sodium, SNa, $\geq 150 \mathrm{mmol} / \mathrm{L}$ [1]) in term neonates is classically associated with inadequate fluid intake, particularly due to insufficient lactation. The main predisposing factors include problems with maternal breast milk synthesis, difficulty with breast milk removal, and low daily breast milk intake [2]. Excessive weight loss, beyond $10 \%$ of birth weight, occurs in approximately $15 \%$ of exclusively breastfed infants [3] and approximately one third of them will be hypernatremic [4]. Diagnosis may be challenging because neonates have less pronounced clinical signs of dehydration [4] and excessive weight loss is not a mandatory finding [5]. The usual clinical presentation includes jaundice, hyperthermia, poor oral intake, low urine output, and lethargy, which are all unspecific signs for a great variety of diseases in the neonatal period [1, 6-8].

The incidence of hypernatremic dehydration is difficult to define. Ergenekon et al. [9] reported neonatal hypernatremic dehydration in $1 \%$ of all deliveries, while Bolat et al. [10] described it as being responsible for $1.8 \%$ of all neonatal admissions. This relatively common condition raises concern due to its potential of causing significant morbidity. Seizures $[6,11]$, acute renal injury [12], cerebral thrombosis, and hemorrhage [4] are among the most significant and potentially deleterious complications.

Besides the complications of the condition itself, reestablishment of plasma tonicity may also lead to serious damage if not done properly. The use of hypotonic fluids is appropriate to dilute the $\mathrm{SNa}$, but cerebral edema may develop when it happens in an untimely manner. Although the literature describes that the maximum rate of SNa reduction should not surpass $0.5-1 \mathrm{mEq} / \mathrm{L} / \mathrm{h}[13,14]$, there is no consensus about proper rehydration strategies in hypernatremic neonates. There are no guidelines as to which extent hypernatremic dehydration may be corrected exclusively by increasing oral feeds, when parenteral fluids are indicated and which parenteral solution is appropriate to avoid excessive SNa correction. A review by Moritz et al. [14], for example, recommends using $0.2 \%$ saline in $5 \%$ dextrose in water for hypernatremia due to inadequate feeding, without specifying according to the degree of hypernatremia and acknowledging that there is no definitive documentation on the optimal rate of SNa reduction. The present systematic review aims at clarifying some of the issues regarding the correction of hypernatremic dehydration, particularly caused by insufficient lactation, in term neonates and the main outcomes of the treatment. 


\section{Methods}

In order to examine the best strategy of treatment for hypernatremia in neonates, we performed a systematic literature review, seeking studies describing which treatment was used, according to the method proposed by The Cochrane Collaboration [15] and the PRISMA guidelines [16]. This systematic review is registered at PROSPERO (registration number: CRD42016034119).

\section{Searching}

The search was performed on the following databases: Clinical Trials, MEDLINE/PubMed, EMBASE, LILACS, and the Cochrane Library. The search was limited to studies published until January 31st, 2016.

The search strategy used at EMBASE was: ("term infant" OR "neonate" /exp OR "neonate" OR "newborn"/exp OR "newborn") AND ("hypernatraemia"/exp OR "hypernatraemia" OR "hypernatremic dehydration"). For the other databases, the search strategy was: (["neonate"] OR ["newborn"] OR ["term infant"] AND ["hypernatremia"]) OR "hypernatremic dehydration". Ongoing studies were identified through searches of Clinical Trials.gov.

\section{Study Selection and Characteristics}

The title and abstracts of studies identified by the search were screened for potential relevance. The full text of all potentially relevant studies was reviewed to determine if they fulfilled the eligibility criteria. Studies were included if: (1) it was a randomized controlled trial (RCT); (2) the study included term neonates treated for hypernatremic dehydration; (3) the study evaluated outcomes considered relevant such as death, cerebral edema, and seizures, which were defined a priori. We excluded studies in which the cause for dehydration was diarrhea as most children with diarrhea have hypotonic (and hyponatremic) dehydration and the focus of the review was hypernatremic dehydration related to inadequate breastfeeding. Renal and tubular function matures after birth, and this maturation is different depending on the gestational age, therefore we excluded preterm neonates or infants beyond the neonatal period that could be a potential confounder to the results.

We anticipated that there would be a small number of RCTs meeting our inclusion criteria. Therefore, if fewer than 5 RCT were identified, the following criteria were applied: open-label trials, nonrandomized controlled trials, or prospective and retrospective case series $(\geq 5$ patients) evaluating relevant outcomes.

Selection of articles was made by 2 independent researchers (A.R.B. and A.D.D.), who evaluated the abstracts identified by the research according to the eligibility criteria. The search was reviewed by a third investigator (C.G.C.) who compared the decisions and solved divergences.

\section{Data Extraction}

Data were abstracted independently by 2 reviewers (A.R.B. and A.D.D.). Information regarding the way of administering the treatment [intravenous (i.v.) or oral], type of fluid used for treatment, rates of complications and outcomes, as well as rate of SNa reduction were collected. Divergences were solved by consensus or, when needed, by the intervention of a third investigator (C.G.C.). When full text was unavailable, contact with the corresponding author was made in order to obtain the paper. Every selected article was evaluated according to the risk of bias. In order to assess the risk of bias, the methodological quality of the included articles was evaluated using the Grading of Recommendations Assessment, Development and Evaluation (GRADE) working group system [17-19]. This tool classifies the quality of outcomes as high, moderate, low, and very low [20] using the risk of bias, inconsistency, indirectness, and imprecision as criteria. 
(C) 2017 The Author(s). Published by S. Karger AG, Basel www.karger.com/bmh

Bischoff et al.: Treatment of Hypernatremia in Breastfeeding Neonates: A Systematic Review

Table 1. Summary of findings from retrospective studies that compared different treatments for hypernatremia in newborns

\begin{tabular}{|c|c|c|c|c|}
\hline & \multicolumn{2}{|l|}{ Bolat [10] } & \multicolumn{2}{|l|}{ Erdemir [22] } \\
\hline Participants & 81 & & $\begin{array}{l}\text { parenteral } \\
\text { treatment } \\
(\mathrm{n}=31)\end{array}$ & \\
\hline Gestational age, weeks & $\geq 37$ & & $\geq 35$ & \\
\hline Mean BW \pm SD, g & $3,450 \pm 283$ & $3470 \pm 275$ & $3,390 \pm 62$ & $3,265 \pm 607$ \\
\hline Range & & & $2,700-4,500$ & $2,500-4,400$ \\
\hline Mean WL \pm SD,$\%$ & $16.8 \pm 4.4$ & $20.4 \pm 6.4$ & $7.5 \pm 6.6$ & $5.0 \pm 3.3$ \\
\hline Range & & & $1-30$ & $1-18$ \\
\hline Mean serum BUN, mg/dL & 40 & 95 & 57 & 41 \\
\hline Range & $4-263$ & $18-178$ & $27-175$ & $17-107$ \\
\hline Treatment & & & i.v. fluids & $\begin{array}{l}\text { breast } \\
\text { milk and } \\
\text { formula }\end{array}$ \\
\hline Bolus NaCl 0.9\% & $1(9)$ & $7(30.4)$ & & \\
\hline i.v. rehydration, $\mathrm{NaCl}, \%$ & 0.3 & 0.45 & & \\
\hline \multicolumn{5}{|l|}{ Rate of correction at $48 \mathrm{~h}$} \\
\hline$\leq 0.5 \mathrm{mmol} / \mathrm{L} / \mathrm{h}$ & 32 & 13 & & \\
\hline$>0.5 \mathrm{mmol} / \mathrm{L} / \mathrm{h}$ & 23 & 10 & & \\
\hline
\end{tabular}

Values are numbers with percentages in parentheses, except where otherwise indicated. Data is displayed when available in the article. BW, body weight; $\mathrm{WL}=$ weight loss; i.v. = intravenous.

Fig. 1. PRISMA flow diagram of the different phases of the systematic review.

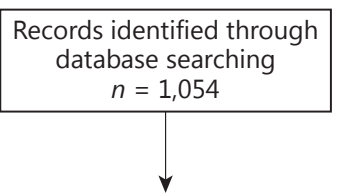

Records after duplicates removed

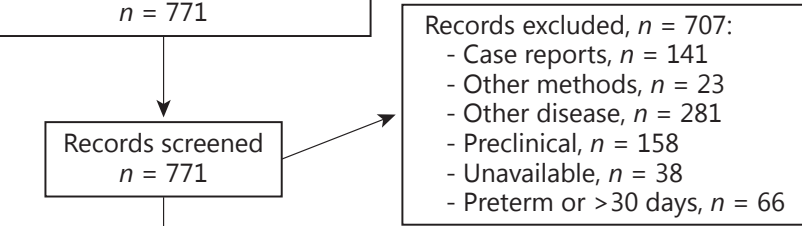

Full-text articles assessed for eligibility $n=64$

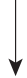

Studies included in qualitative synthesis $n=9$ 
(C) 2017 The Author(s). Published by S. Karger AG, Basel www.karger.com/bmh

Bischoff et al.: Treatment of Hypernatremia in Breastfeeding Neonates: A Systematic Review

Table 2. Summary of findings from articles included in systematic reviews and outcome after treatment of dehydration ${ }^{1}$

\begin{tabular}{|c|c|c|c|c|c|c|c|c|c|c|c|c|c|}
\hline \multirow{2}{*}{$\begin{array}{l}\text { First author } \\
\text { [Ref.] }\end{array}$} & \multirow[t]{2}{*}{$N$} & \multirow{2}{*}{$\begin{array}{l}\text { GA, } \\
\text { weeks }\end{array}$} & \multirow{2}{*}{$\begin{array}{l}\text { Age at } \\
\text { admission², } \\
\text { days }\end{array}$} & \multirow[t]{2}{*}{ Birth weight ${ }^{2}, \mathrm{~g}$} & \multirow{2}{*}{$\begin{array}{l}\text { Weight } \\
\text { loss }^{2}, \%\end{array}$} & \multirow{2}{*}{$\begin{array}{l}\text { Serum sodium², } \\
\mathrm{mEq} / \mathrm{L}\end{array}$} & \multicolumn{3}{|c|}{ Treatment } & \multicolumn{4}{|l|}{ Outcome } \\
\hline & & & & & & & i.v. & oral & both & seizures & AKI & $\begin{array}{l}\text { brain } \\
\text { edema }\end{array}$ & death \\
\hline Bilgin [21] & 149 & term & $4.5 \pm 3.8$ & $3,325 \pm 558$ & $13 \pm 6.3$ & 155 & yes & yes & yes & $7(4.7 \%)$ & 32.9 & $5(3.3 \%)$ & 0 \\
\hline Range & & & $1-27$ & $2,400-5,000$ & $3.3-35.2$ & $150-190$ & & & & & & & \\
\hline Ozdogan [24] & 29 & term & 5.6 & 3,350 & 15.5 & 160.7 & yes & & yes & 1 & 2 & 0 & 0 \\
\hline Range & & & $2-12$ & $2,100-4,400$ & $6-29$ & $150-188$ & & & & & & & \\
\hline $\mathrm{Ng}[23]$ & 5 & term & $4.8 \pm 1.64$ & $3,127 \pm 370$ & & $152.8 \pm 1.3$ & yes & yes & yes & 0 & 0 & 0 & 0 \\
\hline Range & & & $3-6$ & $2,635-3,510$ & $11-14$ & $151-154$ & & & & & & & \\
\hline Peker [28] & 10 & & $6.5 \pm 2.4$ & & & $169.4 \pm 7.8$ & yes & & & 2 & 4 & 0 & 2 \\
\hline Range & & & $3-10$ & & & $160.5-185$ & & & & & & & \\
\hline Yaseen [27] & 29 & $>37$ & $4.9 \pm 2.5$ & $3,084 \pm 435$ & $16.5 \pm 4.1$ & $155 \pm 9.5$ & yes & yes & yes & 1 & 0 & 1 & 0 \\
\hline Range & & & $2-13$ & & $12-29$ & $150-196$ & & & & & & & \\
\hline Oddie [26] & 62 & $>33$ & 6 & $3,467 \pm 537$ & 19.5 & 164 & yes & & & 0 & 0 & 0 & 0 \\
\hline Range & & & $3-17$ & & $8.9-30.9$ & $160-187$ & & & & & & & \\
\hline Yildiz [25] & 15 & term & & $3,096.7 \pm 143$ & $11.4 \pm 1.7$ & $169.2 \pm 6.5$ & $\mathrm{PD}$ & & & 0 & 15 & 0 & 4 \\
\hline Range & & & $4-27$ & & & $158-180$ & & & & & & & \\
\hline
\end{tabular}

${ }^{1}$ Data shown in Table 1 is not displayed. ${ }^{2}$ Values are given as mean \pm SD. Data is displayed when available in the article. AKI, acute kidney injury; GA, gestational age; i.v., intravenous; PD, peritoneal disease.

\section{Results}

The searches yielded 540 results in MEDLINE/PubMed, 18 in LILACS, 472 in EMBASE, 1 in Clinical Trials, and 13 in the Cochrane Library. A total of 771 articles had their title and abstracts reviewed by 2 independent reviewers. Of those, 64 were considered eligible for fulltext review and 9 articles met the inclusion criteria and were included by consensus (Fig. 1). There were no systematic reviews focusing on specifics of treatment and its outcomes and no randomized clinical trials. There were 7 retrospective $[10,21-25]$ and 2 prospective studies $[26,27]$ with $\geq 5$ patients included. Only 2 articles performed direct comparisons regarding different treatments $[10,22]$ (Table 1), while the remaining studies described types of treatment and outcomes and were kept in the review for descriptive purposes only (Table 2). One article was a case series of neonates with severe hypernatremia treated with peritoneal dialysis (PD), and we decided to keep it in the review due to its data regarding outcomes of this specific therapy [25]. Three articles included late preterm infants [22, 26, 28] and we also decided to keep it in the review as these sample included otherwise healthy neonates whose only likely predisposing factor related to hypernatremic dehydration was inadequate breastfeeding. These infants had a birth weight $>2,000 \mathrm{~g}$ and were not admitted for other issues related to prematurity.

The studies included a minimum of 5 to a maximum of 149 patients, totalizing 455 patients among the 9 selected studies. There were 208 (45.7\%) males, 133 (29.2\%) females, and $114(25 \%)$ patients were not classified according to sex. Gestational age ranged from 35 to 42 weeks, birth weight ranged from 2,100 to 5,000 g, and age at diagnosis/admission ranged from 1 to 27 days. The percentage of weight loss ranged from 1 to $35.2 \%$, and serum creatinine and blood urea nitrogen at admission were described from 0.22 to 8 and from 4 to $263 \mathrm{mg} / \mathrm{dL}$, respectively. Symptoms at admission were described as jaundice in 182 (40\%) and fever in 183 (40.2\%). Other presenting symptoms included weight loss, poor feeding, 
irritability, restlessness, lethargy, decreased urine output, constipation, vomiting, and seizures.

The study by Bolat etal. [10] was the most detailed regarding treatment, rate of correction of $\mathrm{SNa}$, and outcomes. It consisted of a retrospective analysis and patients were analyzed according to 3 ranges of SNa: groups 1 and 2 (both data described in Table 1), and group 3 ( $n=3$; SNa between 171-189 $\mathrm{mEq} / \mathrm{L}$ ). Adverse effects were more prevalent when the rate of correction exceeded $0.5 \mathrm{mEq} / \mathrm{L} / \mathrm{h}$. Patients in group 3 were treated with bolus of $0.9 \%$ saline due to hypovolemic shock and further management included $0.6 \%$ saline that was further changed to $0.9 \%$ saline due to a drastic decrease of SNa [10]. Logistic regression analysis was performed to analyze independent risk factors for seizures and death: SNa $>160 \mathrm{mEq} / \mathrm{L}$ at admission and rate of correction $>0.5 \mathrm{mEq} / \mathrm{L} / \mathrm{h}$ had an odds ratio of 1.9 and 4.3 , respectively.

Erdemir et al. [22] aimed at comparing oral and i.v. rehydration through a retrospective study. Data were analyzed according to the treatment that was instituted: 44 (58.6\%) treated with breast milk and/or oral formula and 31 (41.4\%) treated with i.v. fluid (4/510\% dextrose $+1 / 5$ normal saline). There was a significant difference in the rate of correction between both groups at 12 and $24 \mathrm{~h}$. For instance, at $12 \mathrm{~h}, 93.5 \%$ of the patients in the i.v. fluids group had what it was considered a nonsafe drop in SNa ( $>0.5 \mathrm{mEq} / \mathrm{L} / \mathrm{h})$ compared to $56.8 \%$ in the oral therapy group. When considering only patients with higher SNa ( $>155 \mathrm{mEq} / \mathrm{L})$, all patients treated with i.v. fluids had a nonsafe drop when compared to only $30.7 \%$ of patients in the oral therapy group at $24 \mathrm{~h}$. Only 1 patient (i.v. fluid group) developed seizures and cerebral edema. He had a $12 \mathrm{mEq} / \mathrm{L}$ drop in $\mathrm{SNa}$ at $12 \mathrm{~h}$. No further adverse effects of treatment were described and there was no follow-up for neurodevelopmental evaluation [22].

In the study by Bilgin et al. [21], there was no thorough description of the treatment used, stated only as oral rehydration or i.v. fluid according to the severity. Seven (4.7\%) patients developed seizures within $24 \mathrm{~h}$ of treatment and 5 patients (3.3\%) showed signs of cerebral edema on computed tomography (CT) evaluation. The rate of correction of hypernatremia was not specified [21]. In a retrospective study by Ozdogan et al. [24], 1 patient presented seizures during the rehydration phase (sodium at admission was $188 \mathrm{mEq} / \mathrm{L}$ ), but there was no description of the rate of SNa drop or the treatment that was used. Patients were treated with fluid bolus $\mathrm{NaCl} 0.9 \%$ and oral feeds or free water for $48-72 \mathrm{~h}$ as well as saline boluses. Compared outcomes after treatment were not described [24].

A case series by $\mathrm{Ng}$ et al. [23] described 4 patients treated with breast milk and artificial formula supplementation and 1 patient treated with additional i.v. fluids, without description of the characteristics of the fluid. There were no complications in this sample, which could be attributed to the relatively low level of hypernatremia and the more conservative treatment used.

The study by Peker et al. [28] included 10 newborns ( 1 preterm, $60 \%$ of small for gestational age). Fluid with a sodium concentration of 75-100 $\mathrm{mEq} / \mathrm{L}$ was administered to 4 neonates and it took more than $72 \mathrm{~h}$ to achieve SNa concentrations lower than $150 \mathrm{mEq} / \mathrm{L}$. In 6 cases, after the calculation of maintenance and lost fluid, $5 \%$ dextrose and $0.2 \% \mathrm{NaCl}$ solutions were administered. In this group, normal SNa was reached earlier, with a mean period of $48 \mathrm{~h}$. Two of the hypernatremic newborns died during the study (due to meningitis and kernicterus) [28].

A prospective nonrandomized study conducted by Yaseen et al. [27] included 10 patients (35\%) receiving oral rehydration, 11 patients (38\%) receiving i.v. rehydration, described only as hypotonic, and $8(28 \%)$ receiving both oral and i.v. rehydration. There was a description of fast rehydration with hypotonic fluids causing seizures and coma in 1 patient, and head CT scan showed signs of brain edema [27]. 
A prospective population-based surveillance study by Oddie et al. [26] described i.v. bolus infusions administered in 14 patients while 31 had ongoing maintenance fluids. There were no adverse effects related to treatment and the authors described a mean drop of 12.7 $\mathrm{mEq} / \mathrm{L}$ in $24 \mathrm{~h}$ of SNa [26].

Yildiz et al. [25] reviewed the medical records of 15 neonates with acute kidney injury and hypernatremic dehydration due to inadequate breast milk intake, who were treated with acute PD (mean duration: 6.36 days). Significant comorbidities were present in 12 infants, and 4 did not survive. All patients were treated initially with isotonic saline solution delivered twice intravenously at a dose of $10-20 \mathrm{~mL} / \mathrm{kg}$ over $1 \mathrm{~h}$. The decision to begin dialysis was made if, after at least $12 \mathrm{~h}$, conservative management failed to control fluid and electrolyte balance. SNa declined to $160.8 \pm 6.7 \mathrm{mg} / \mathrm{dL}$ (range: $152-170$ ) at the end of $24 \mathrm{~h}$ and to $152 \pm$ $7.1 \mathrm{mg} / \mathrm{dL}$ (range: 142-163) after $48 \mathrm{~h}$, lower than $15 \mathrm{mEq} / \mathrm{L}$ per day.

\section{Discussion}

Hypernatremic dehydration is a potentially serious complication of breastfeeding due to inadequate lactation [4]. A large number of retrospective studies have highlighted the importance of recognizing this diagnosis, focusing mainly on the description of clinical signs and symptoms at presentation and risk factors [2, 8, 11,29-31]. However, this systematic review showed that there is a scarcity of good quality studies about the treatment of this condition. There is no randomized clinical trial focusing on the treatment of hypernatremia in term neonates. Only 2 retrospective studies provided some comparison among different treatment strategies and a more thorough evaluation regarding the rate of correction of SNa [10,22], whereas the remaining studies provided descriptions of treatment options and outcomes without details of which solution was used [21, 23-28].

The proposal of this systematic review was to critically assess the available literature on hypernatremic dehydration in term neonates, seeking to establish the best available intervention and its efficacy and safety. The studies investigated were very heterogeneous and included small numbers of patients with poor description of outcomes and clinical manifestations. Despite the limitations, it sought to critically evaluate the best available evidence. Among the selected studies, there was a great disparity in the outcomes used by the authors, which included predominantly limited reporting of results, which affected the comparison between different papers and thus not obtaining sufficient data to perform meta-analysis of any variable. Therefore, quantitative assessment of heterogeneity of studies as well as assessment of their risk of bias was not performed. This intrinsic limitation arises from the great variability of studies performed and available for review. For the above mentioned reasons, according to GRADE system, the quality of the included studies is low (2 plus, ++ ).

Three studies included late preterm neonates ( $>35$ weeks) $[22,26,28]$, but we kept them in the review as a way of preserving a greater number of patients. Although it was not the focus of this study, it is important to acknowledge that late preterm neonates are also subject to hypernatremia dehydration due to insufficient lactation and that there might be interesting differences related to gestational age particularities of renal function maturity [32,33]. Due to these complicated patterns of renal maturation and other possible confounders in the preterm population, we restricted the review solely to term neonates.

Hypernatremia leads to an efflux of fluid from the intracellular to the extracellular compartment, with transient cell shrinkage and cerebral volume decrease [34]. When chronically installed (more than 1-3 days), there is an increased production of idiogenic osmoles that help restore brain volume [35]. Rapid correction of hypernatremia or administration of 

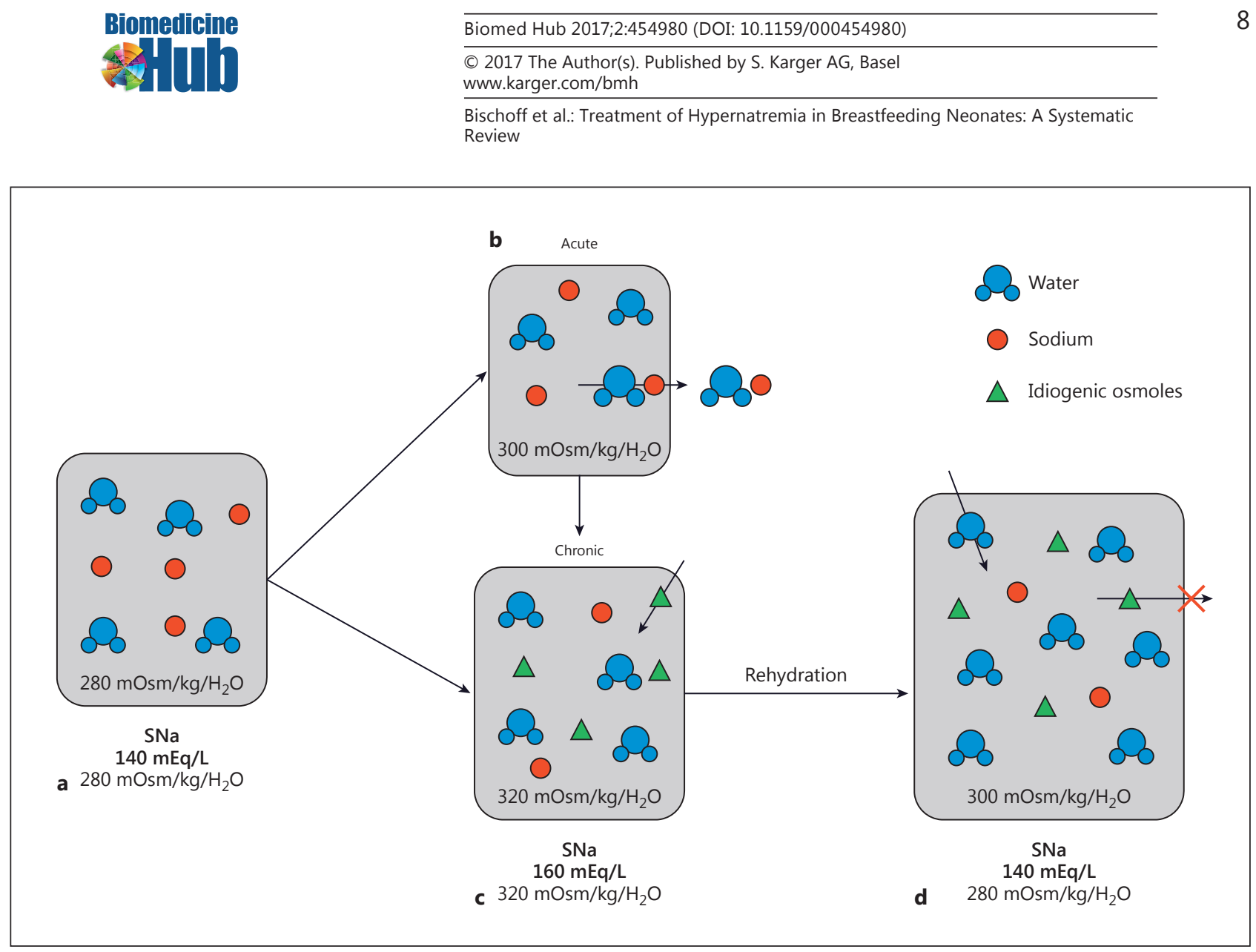

Fig. 2. a Similar tonicity between the plasma and the cell. b Acute hypernatremia: efflux of sodium and water. c Chronic hypernatremia: idiogenic osmoles enter into the cell to maintain osmolarity and cell volume. d Rapid rehydration: relative inability to exclude the idiogenic osmoles and influx of water leads to edema.

excessively hypotonic fluids may lead to brain edema due to the brain's inability to remove the idiogenic osmoles [34, 35] (Fig. 2).

The main stem of treatment consists of increasing free water availability to dilute excessive SNa. Moreover, as volume depletion is frequently associated, fluid resuscitation with normal saline or colloid should be instituted prior to the correction of free water deficit $[14,34]$. Moritz and Ayus [34] acknowledge different strategies according to the cause of hypernatremia: those with sodium overload or renal concentrating defect require more hypotonic fluids than those with volume depletion and normal renal concentrating function. Urinary sodium excretion is inversely related to gestational age and studies show that tubular function is mature in term neonates [32, 33].

Apart from the limitations mentioned above, it appears that neonates with more severe hypernatremia are the ones at greater risk of severe adverse effects of treatment. Still, the degree of hypernatremia itself is not the sole predictor of adverse outcomes. The rate of SNa drop plays a major role. In the study by Bolat et al. [10], a rate of SNa correction beyond $0.5 \mathrm{mEq} / \mathrm{L} / \mathrm{h}$ was significantly associated with adverse outcomes, with an impressive odds ratio of 4.3 for death and neonatal seizures. In Erdemir et al.'s [22] study, a rate of correction beyond $0.5 \mathrm{mEq} / \mathrm{L} / \mathrm{h}$ was more prevalent in the group treated with i.v. fluids. Yaseen et al.'s [27] sample of patients included newborns with a SNa as high as 196 $\mathrm{mEq} / \mathrm{L}$; however, adverse effects were observed in a patient with a SNa of $160 \mathrm{mEq} / \mathrm{L}$, described as having received fast rehydration with glucose and hypotonic fluids. Although rate thresholds have been traditionally described as $0.5-1 \mathrm{mEq} / \mathrm{L} / \mathrm{h}[13,14]$, there is not 
enough evidence to support these recommendations. For instance, in this review, we were not able to gather enough data to attempt to construct a ROC curve to determine an optimal rate threshold.

The estimation of free water deficit, which takes into consideration lean body weight and desired $\mathrm{SNa}$, is an interesting strategy to calculate the amount of fluid necessary to correct the SNa [14]. The tonicity of the fluid used to correct the water deficit should be tailored according to the severity of hypernatremia. Bell et al. [36] recommend a sodium drop of less than $15 \mathrm{mEq} / \mathrm{L}$ during a 24-hour period, correcting the free water deficit with hypotonic fluid. Although there is no consensus about the optimal rate of SNa drop in hypernatremic term neonates, it is clear from the studies presented that a slower correction appears to be safer. In fact, a close monitoring of SNa should be strongly encouraged.

\section{Conclusions and Future Directions}

Taken the pathophysiological cause of hypernatremia in term neonates and the increased incidence of adverse outcomes in patients with rapid correction of $\mathrm{SNa}$, it seems that a more conservative approach, with fluids that are mildly hypotonic, may be more appropriate in those with more severe hypernatremia. Furthermore, careful and frequent monitoring of SNa during the rehydration phase is imperative. We suggest that adjustments of fluid therapy should be carried out during treatment to avoid SNa drops greater than $0.5 \mathrm{mEq} / \mathrm{L} / \mathrm{h}$. Questions as to when increasing enteral feeds is not enough and parenteral fluids are indicated remain unanswered. In this scenario, we strongly recommend that large prospective studies and randomized clinical trials should be done in order to clarify these questions. In addition, as highlighted by some of the severe adverse outcomes related to the condition and its treatment, the prevention of hypernatremic dehydration associated with inadequate breastfeeding is judicious. Lactation support and education, as well as careful follow-up and weight measurements, are likely to be helpful not only as preventative measures but also in early identification of vulnerable infants.

\section{Disclosure Statement}

The authors have no conflicts of interest to disclose.

\section{References}

1 Moritz ML, Manole MD, Bogen DL, Ayus JC: Breastfeeding-associated hypernatremia: are we missing the diagnosis? Pediatrics 2005;116:e343-e347.

$>2$ Livingstone VH, Willis CE, Abdel-Wareth LO, Thiessen P, Lockitch G: Neonatal hypernatremic dehydration associated with breast-feeding malnutrition: a retrospective survey. CMAJ 2000;162:647-652.

$>3$ Chantry CJ, Nommsen-Rivers LA, Peerson JM, Cohen RJ, Dewey KG: Excess weight loss in first-born breastfed newborns relates to maternal intrapartum fluid balance. Pediatrics 2011;127:e171-e179.

4 Moritz ML: Preventing breastfeeding-associated hypernatraemia: an argument for supplemental feeding. Arch Dis Child Fetal Neonatal Ed 2013;98:F378-F379.

-5 van Dommelen P, van Wouwe JP, Breuning-Boers JM, van Buuren S, Verkerk PH: Reference chart for relative weight change to detect hypernatraemic dehydration. Arch Dis Child 2007;92:490-494.

6 Lavagno C, Camozzi P, Renzi S, Lava SA, Simonetti GD, Bianchetti MG, Milani GP: Breastfeeding-associated hypernatremia: a systematic review of the literature. J Hum Lact 2016;32:67-74.

-7 Trotman H, Lord C, Barton M, Antoine M: Hypernatraemic dehydration in Jamaican breastfed neonates: a 12-year review in a baby-friendly hospital. Ann Trop Paediatr 2004;24:295-300. 
8 Uras N, Karadag A, Dogan G, Tonbul A, Tatli MM: Moderate hypernatremic dehydration in newborn infants: retrospective evaluation of 64 cases. J Matern Fetal Neonatal Med 2007;20:449-452.

-9 Ergenekon E, Unal S, Gucuyener K, Soysal SE, Koc E, Okumus N, Turkyilmaz C, Onal E, Atalay Y: Hypernatremic dehydration in the newborn period and long-term follow up. Pediatr Int 2007;49:19-23.

-10 Bolat F, Oflaz MB, Guven AS, Ozdemir G, Alaygut D, Dogan MT, Icagasoglu FD, Cevit O, Gultekin A: What is the safe approach for neonatal hypernatremic dehydration? A retrospective study from a neonatal intensive care unit. Pediatr Emerg Care 2013;29:808-813.

11 Unal S, Arhan E, Kara N, Uncu N, Aliefendioglu D: Breast-feeding-associated hypernatremia: retrospective analysis of 169 term newborns. Pediatr Int 2008;50:29-34.

-12 Barman H, Das BK, Duwarah SG: Acute kidney injury in hypernatremic dehydration in exclusively breastfed babies: don't ignore it! J Clin Neonatol 2014;3:124-125.

13 Fang C, Mao J, Dai Y, Xia Y, Fu H, Chen Y, Wang Y, Liu A: Fluid management of hypernatraemic dehydration to prevent cerebral oedema: a retrospective case control study of 97 children in China. J Paediatr Child Health 2010;46:301-303.

14 Moritz ML, Ayus JC: Disorders of water metabolism in children: hyponatremia and hypernatremia. Pediatr Rev 2002;23:371-380.

15 Higgins JPT, Green S (eds): Cochrane Handbook for Systematic Reviews of Interventions Version 5.1.0 (updated March 2011). The Cochrane Collaboration, 2011.

-16 Moher D, Liberati A, Tetzlaff J, Altman DG, Group P: Preferred reporting items for systematic reviews and meta-analyses: the PRISMA statement. PLoS Med 2009;6:e1000097.

17 Guyatt G, Vist G, Falck-Ytter Y, Kunz R, Magrini N, Schunemann H: An emerging consensus on grading recommendations? ACP J Club 2006;144:A8-A9.

18 Guyatt GH, Oxman AD, Schunemann HJ, Tugwell P, Knottnerus A: GRADE guidelines: a new series of articles in the Journal of Clinical Epidemiology. J Clin Epidemiol 2011;64:380-382.

19 Guyatt GH, Oxman AD, Vist GE, Kunz R, Falck-Ytter Y, Alonso-Coello P, Schunemann HJ, Group GW: GRADE: an emerging consensus on rating quality of evidence and strength of recommendations. BMJ 2008;336:924-926.

-20 Balshem H, Helfand M, Schunemann HJ, Oxman AD, Kunz R, Brozek J, Vist GE, Falck-Ytter Y, Meerpohl J, Norris S, Guyatt GH: GRADE guidelines: 3. Rating the quality of evidence. J Clin Epidemiol 2011;64:401-406.

-21 Bilgin LK, Akcay F, Altinkaynak K, Altindag H: Hypernatremia in breastfed newborns: a review of 149 cases. J Trop Pediatr 2012;58:332-334.

-22 Erdemir A, Kahramaner Z, Cosar H, Turkoglu E, Kanik A, Sutcuoglu S, Ozer EA: Comparison of oral and intravenous fluid therapy in newborns with hypernatremic dehydration. J Matern Fetal Neonatal Med 2014;27: 491-494.

-23 Ng PC, Chan HB, Fok TF, Lee CH, Chan KM, Wong W, Cheung KL: Early onset of hypernatraemic dehydration and fever in exclusively breast-fed infants. J Paediatr Child Health 1999;35:585-587.

-24 Ozdogan T, Iscan M, Ellikcioglu C, Yildiz E: Hypernatraemic dehydration in breast-fed neonates. Arch Dis Child 2006;91:1041.

25 Yildiz N, Erguven M, Yildiz M, Ozdogan T, Turhan P: Acute peritoneal dialysis in neonates with acute kidney injury and hypernatremic dehydration. Perit Dial Int 2013;33:290-296.

26 Oddie SJ, Craven V, Deakin K, Westman J, Scally A: Severe neonatal hypernatraemia: a population based study. Arch Dis Child Fetal Neonatal Ed 2013;98:F384-F387.

-27 Yaseen H, Salem M, Darwich M: Clinical presentation of hypernatremic dehydration in exclusively breast-fed neonates. Indian J Pediatr 2004;71:1059-1062.

28 Peker E, Kirimi E, Tuncer O, Ceylan A: Severe hypernatremia in newborns due to salting. Eur J Pediatr 2010; 169:829-832.

29 Oddie S, Richmond S, Coulthard M: Hypernatraemic dehydration and breast feeding: a population study. Arch Dis Child 2001;85:318-320.

30 Koklu E, Gunes T, Ozturk MA, Kose M, Kurtoglu S, Yuksel F: A review of 116 cases of breastfeeding-associated hypernatremia in rural area of central Turkey. J Trop Pediatr 2007;53:347-350.

-31 Bhat SR, Lewis P, David A, Liza SM: Dehydration and hypernatremia in breast-fed term healthy neonates. Indian J Pediatr 2006;73:39-41.

-32 Gattineni J, Baum M: Developmental changes in renal tubular transport - an overview. Pediatr Nephrol 2013; 30:2085-2098.

33 Lava SA, Bianchetti MG, Simonetti GD: Salt intake in children and its consequences on blood pressure. Pediatr Nephrol 2015;30:1389-1396.

34 Moritz ML, Ayus JC: Preventing neurological complications from dysnatremias in children. Pediatr Nephrol 2005;20:1687-1700.

-35 Ben-Shalom E, Toker O, Schwartz S: Hypernatremic dehydration in young children: is there a solution? Isr Med Assoc J 2016;18:95-99.

-36 Bell EF, Segar JL, Oh W: Fluid and electrolyte management; in MacDonald MG, Seshia MMK (eds): Avery's Neonatology. Pathophysiology and Management of the Newborn. Lippincott Williams \& Wilkins, 2015, pp 265-279. 